\title{
The Bologna Process: \\ Question of Priorities and Relevance
}

Mohammed Ali Shallal

Scientific Research and Development Centre, Nawroz University, Duhok, Kurdistan Region - Iraq

\begin{abstract}
Recent trends in some higher education institutions (HEIs) have reflected the tendency to adopt, or to embark on the path of, the Bologna Process (BP). This paper considers the tools and operations involved, presents brief aspects of $\mathrm{BP}$ and attempts to shed light on the requirements with the purpose of creating an acceptable picture of the processes and possibly prioritizing them. It also questions the relevance of some BP aspects to HEIs in the region and the appropriateness of using the title of 'The Bologna Process' to describe the currently attempted implementations. Issues related to the revision of curriculum structures as well as the introduction of flexibility into the curricula in light of accreditation standards are also briefly addressed.
\end{abstract}

KEYWORDS: Nawroz University, Bologna Process, ESG, ECTS, Outcome-Based Education (OBE), Academic Accreditation.

\section{Introduction}

It is generally acknowledged that higher education (HE) in the area faces a number of significant challenges. These challenges may be categorized under general main headings, which include: ${ }^{11]}$

- vision for improving education

- mode of education \& curricula

- faculty capacities

- student assessment

- quality of research

- accreditation progress

Regardless of how accurately these concerns may have been expressed or the extent of their validity, they do indicate that reforms are required and that the modernization and development of the local HE system/curricula are called for. A significant feature of reform and development is in the drive to produce evidence of effectiveness \& efficiency in a HEI, known as institutional effectiveness (IE). IE is based on outcomes assessment which measures both institutional and academic quality.

Globally, IE is pursued in most HEIs in compliance with criteria usually outlined by accreditation and/or quality assurance (QA) agencies. Academic program assessment is one of the essential components of IE. The most important assessment is that of learning outcomes (LOs).

\footnotetext{
Academic Journal of Nawroz University

(AJNU) Volume 8, No 3 (2019).

Regular research paper : Published 11 June 2019

Corresponding author's e-mail : mashallal44@gmail.com

Copyright (C2018 Mohammed Ali Shallal.

This is an open access article distributed under the

Creative Commons Attribution License.
}

LOs may be specified at various levels, such as:

- institution (general education LOs: GELOs)

- program (program LOs: PLOs)

- course/module (course/module LOs: CLOs/MLOs)

- unit or lecture LOs

- ......

In Europe, HEIs are obliged under the Bologna Agreement to adopt the LO approaches, among other obligations related to HEIs' functions.

Some HEIs have recently embarked on a path of adopting the BP, possibly giving the implication that such embarkations provide solutions for problems and concerns. Naturally such moves, if proper, ought to be encouraged, since HE schemes and curriculum frameworks in general require regular revisions and improvements in various related areas.

This paper looks at the main BP features in general, with teaching and learning (T\&L) issues in particular. It then considers suggestions for prioritizing the $\mathrm{BP}$ aspects to focus on and preparing for a possible implementation plan. Attention is drawn to some questions along the path, such as including more flexibility into the currently relatively rigid curriculum structures, paving the way for more choices towards satisfying the graduation requirements, which are also in accordance with the BP.

Section 2 looks at some BP features through addressing the tools that it is based on with an outline of the priorities envisaged to be related to the matter at hand in this paper, i.e. the question of priorities and relevance. 
Section 3 considers the relevance of BP features outlined in section 2 to HEIs in the region. It then considers suggestions of possible areas and priorities to be focused on during the initial stages where due emphasis ought to be given to preparing the necessary background.

The appendix shows a glossary of some related terms used in this paper, extracted mainly from the ECTS document. [2]

\section{The Bologna Process: Main Tools}

The BP, named after the Bologna Declaration signed in the Italian city of Bologna in 1999, is an intergovernmental process involving European countries aiming at the creation of the European Higher Education Area (EHEA). Focus of BP is on:

- easier recognition of qualifications and periods of study, tool: ECTS.

- strengthened QA, tool: European Standards and Guidelines for Quality Assurance (ESG).

- the three cycle system (bachelor/master/doctorate), tool: National Qualifications Frameworks (NQF).

Below is a brief review of the main features and/or purposes of each of the three tools, namely ECTS, ESG, and NQF. These features are extracted from their corresponding main documents available on the web, where more detailed information may be obtained. [2-5]

\subsection{ECTS}

ECTS is a tool of the EHEA for making studies \& courses more transparent and thus helping to enhance the quality of HE.

Among the main features of ECTS are:

- It is the national credit system in most countries of the EHEA, links study credits with both LOs \& student workload and includes the attainment of LOs in assessment procedures.

- Encourages the paradigm shift from a teachercentred to a learner-centred approach, thus allowing students greater autonomy and responsibility.

- Facilitates the mobility of students by easing the recognition of qualifications.

- Makes it possible to integrate different types of learning in a life-long learning (LLL) perspective.

Each of these features may be elaborated on further, with the aid of certain supporting documents, such as the Lisbon Recognition Convention (LRC). ${ }^{[6]}$

\subsection{ESG}

ESG are a set of standards and guidelines for internal and external QA in HE. The ESG provide guidance, covering the areas which are vital for successful quality provision and learning environments in HE. [3]

The ESG should be considered in a broader context that also involves QFs and ECTS that also contribute to promoting the transparency in HE in the EHEA.

Standards 1.2, 1.3, 1.4 and the associated guidelines refer to areas related to ECTS (in particular program design, student-centred learning (SCL), teaching and assessment and student admission, progression, recognition and certification). [2]

\subsection{NQF}

An instrument for the classification of qualifications according to a set of criteria for specified levels of learning achieved. ${ }^{[4,5]} \mathrm{NQF}$ give details of the attributes and LOs that graduates of each level need to have, based on learning domains.

\section{Suggestions for Priorities and a Plan 3.1 Issues Involved}

The previous section outlined the main features that $\mathrm{BP}$, through ECTS, considers to be of particular significance. Below are brief expansions, outlining possible difficulties, concerns and/or requirements for their implementation.

a. ECTS credits and linkage to LOs, workload and assessment, place the students at the centre of the educational process, aiming at enhancing their responsibility \& critical ability through an outcomebased approach.

b. Shift to SCL and creation of flexible learning pathways, in compliance with accreditation standards, international guidelines and trends.

c. Facilitation of student mobility, within an institution or country, from institution to institution, from country to country, \& between different educational sectors and contexts of learning, through recognition and credit transfer. Credit transfer is a key to successful studymobility and it requires that institutions, colleges, departments make agreements which guarantee automatic recognition \& transfer of credits.

d. Integration of different types of learning in a LLL perspective, credits accumulated from learning activities carried out in formal, informal and nonformal contexts to obtain qualifications, as required by the degree-awarding institution, or to document personal achievements.

Features $\mathbf{a}$ and $\mathbf{b}$ require faculty skills, expertise, and experience; while features $\mathbf{c}$ and $\mathbf{d}$ additionally require recognition of prior experience \& learning through the various (i.e. formal, informal and non-formal) contexts, as well as the preparation of necessary regulations. ${ }^{[6]}$

\subsection{Suggestions for a Plan}

From the requirements outlined in the previous section and in light of the concerns expressed in section 1, it is 
obvious that the embarkation on the $\mathrm{BP}$ path requires some hard work to prepare the background first. Clearly faculty skills, expertise and experience coupled with the ability and readiness of the student/learner body are among the important prerequisites.

Given that ECTS credits calculation for a learning component (e.g. a course) is based on the volume of learning expressed by the defined LOs for that component \& the subsequent associated workload based on the activities and assessments/QA considerations that follow, the calculation of credits for any component as a first step, without due attention to involve all related aspects, may not be very realistic.

The determination of the various types of LOs (outlined in section 1) comes early and in an order dictated by the outcomes pyramid which has the mission and objectives of the institution at the top, with proper alignments [7]. Therefore, a learning component's LOs should first be compatible with the mission and objectives of the component itself, the program, the college, and the HEI.

As a consequence, the following broadly expressed tasks are suggested (with or without BP) some of which may be dealt with in parallel based on a suitable time plan [12]:

a. Initiation of an OBE environment.

b. Revision of all overall curricula structures based on 15-week semester-course schemes in light of accreditation standards and international guidelines and trends, by including

- general education (GE) components

- electives at the GE and specialization levels of a program structure to facilitate choices (possibly with tracks and/or concentrations) [14]

- the prerequisite conditions for all components in the structure, with clear pathways defined

- study systems that are based on the concept of accumulation of credits rather than predetermined semester/year structures

all of which would certainly require student academic advising, additional courses, administrative tasks and regulations.

c. Organization of seminars and workshops in related fields for faculty capacity building in a timely manner.

d. Preparation of the details for various curriculum components such as LOs, the ECTS credits (if adopted), course plans, course/program catalogs, course reports, IE manuals, other documents and requirements. $[2,7,11]$

e. Preparation for, and performance of, QA related aspects such as internal and external assessments which may be based on the ESG, self-assessment reports/reviews (SARs), regulations, etc. [3]

\section{Summary \& Conclusions}

\subsection{Summary}

- The paper has attempted to present issues related to the implementation of BP in HEIs, with some points of view expressed on the subject. Naturally, differences in opinion, criticisms or disagreements would be expected and indeed desired; after all 'negative feedback stabilizes a system', as a control engineer may say!

- It is important to get the priorities right and benefit from the positive aspects of other countries experiences, such as the $\mathrm{BP}$ which is certainly one excellent example. It is also vital to address the specific needs and local defining characteristics of the HEI and the community by choosing what is relevant and excluding, or at least knowingly postponing, other aspects that are not so appropriate for the HEIs in the region or which the HEIs are not currently capable of meeting.

- The alignment between curriculum components at various levels should be taken into consideration and emphasized. [7]

\subsection{Conclusions}

i. The adoption of the BP path will not be realistic or necessarily successful without full consideration of the $\mathrm{BP}$ features, implications and requirements. It may not even be appropriate to be called a 'Bologna Process' without such a holistic environment, which may be difficult to find in the region, if at all!

ii. Adopting 'measures of excellence' for processes that may not be 'excellent' themselves in the first place is questionable. ${ }^{[10]}$ Care ought to be taken to avoid 'the emperor's new clothes' phenomenon. [8]

iii. The mere arithmetical conversion of the currently adopted CrHrs in HEIs to ECTS 'credits', for example, does not create a BP environment and does not necessarily reflect academic quality in the institution or programs. Similarly, the adoption of schemes other than BP does not mean that the institution or its programs are not of high academic quality.

iv. Any overemphasis on the way ECTS 'credits' are computed could lead, according to Goodhart's law

'When a measure becomes a target,

it ceases to be a good measure'

to a situation where the LOs and related indicators become targets themselves, with the possibility of 'acrobatic arithmetical maneuvers' being exercised in obtaining evidence for the attainment of LOs or associated indicators, thereby weakening the effectiveness of measurements in the first place. ${ }^{[9]}$

Examples of this may be

- teaching to the test, and

- chasing the indicators. 
v. The ESG guidelines on both internal and external QA are broad enough that they can serve as guiding tools also for non-EHEA countries [13], and may thus be adapted, as far as these two aspects of QA are concerned, without contradicting accreditation standards and criteria. This may not be the case with some features of ECTS that are more appropriate or relevant to the aims and objectives of the EHEA: e.g. student mobility, LLL (integrating different types of learning, prior learning \& experience) and accumulation of credits through informal and nonformal means. These features require channels for opportunities, recognition processes and regulations.

vi. Academic QA/accreditation plans, efforts and results may serve as additional measures for the institutional effectiveness performance of a HEI, possibly as another domain with appropriate weights and indicators in the national university ranking (NUR)?

\section{References}

1. "Towards excellence in medical education and health care", Report on the Workshop on accreditation of medical education in Iraq, Amman, Jordan 31 March - 1 April 2016.

2. The European Credit Transfer and Accumulation System (ECTS), ECTS Users' Guide 2015.

3. Standards and Guidelines for Quality Assurance in the European Higher Education Area (ESG). (2015), Brussels, Belgium.

4. A Framework for Qualifications of the European Higher Education Area, Bologna Working Group on Qualifications Frameworks, 2005.

5. Development of national qualifications frameworks in Europe, Luxembourg: Publications Office of the European Union, 2012.

6. The European Recognition Manual for Higher Education Institutions, Second edition, 2016.

7. Mohammed Ali Shallal, "Alignment of Curriculum Elements at the Course Level: Two Useful Tools", Academic Journal of Nawroz University (AJNU) Volume 7, No 1, 2018.

8. Prideaux, D. "The emperor's new clothes: from objectives to outcomes", Medical Education, 2000.

9. David Woodhouse, "Using and Misusing Data in Higher Education", CAA Quality Series No. 7, May 2014. 10. Hamish Coates, "Excellent Measures Precede Measures of Excellence", Journal of Higher Education Policy and Management 29(1), January 2006.

11. CAA, Commission for Academic Accreditation, http://www.caa.ae

12. Mohammed Ali Shallal, "On the Path of Academic Accreditation: An Outline of a Two-Phase Plan ", Academic Journal of Nawroz University (AJNU) Volume 6, No 3, 2017.
13. Liviu Matei, Julia Iwinska, "Handbook of Quality Assurance in Higher Education, A Practical Handbook", Central European University Yehuda Elkana Center for Higher Education Budapest, Hungary 2016.

14. Mohammed Ali Shallal, "Trends in Undergraduate Program Curriculum Frameworks", Academic Journal of Nawroz University (AJNU) Volume 7, No 3, 2018.

\section{Appendix Glossary [2]}

Accumulation of credits The process of collecting credits awarded for achieving the learning outcomes of educational components in formal contexts and for other learning activities carried out in informal and non-formal contexts. A student can accumulate credits in order to obtain qualifications, as required by the degree-awarding institution, or to document personal achievements for lifelong learning purposes.

Course Catalog Includes general information on the institution, its resources and services, as well as academic information on its programs \& individual educational components

Credit (ECTS) ECTS credits express the volume of learning based on the defined learning outcomes and their associated workload. 60 ECTS credits are allocated to the learning outcomes and associated workload of a full-time academic year or its equivalent, which normally comprises a number of educational components to which credits (on the basis of the learning outcomes and workload) are allocated. ECTS credits are generally expressed in whole numbers.

Credit mobility The mobility of an exchange student, who stays at a host institution for a period, during which $\mathrm{s} /$ he can carry out activities awarding academic credits, which are then recognised by the home institution.

Credit transfer A process that allows credit awarded by one higher education awarding body to be recognised and count towards the requirements of a program at another institution; or that allows credit gained on a particular program to contribute towards the requirements of a different one.

CrHr One hour lecture, or two/three hour lab over a 15 week semester are regarded as one semester $\mathrm{CrHr}$.

Cycle (Level) Descriptors Generic statements about the expected outcomes for each of the three cycles. A good example of general cycle (level) descriptors are the socalled Dublin Descriptors, which have served as one of the foundations (along with ECTS) for the Framework for Qualifications of the European Higher Education Area.

European Credit Transfer and Accumulation System (ECTS) A learner-centred system for credit accumulation and transfer, based on the principle of transparency of learning, teaching and assessment processes. Its objective is to facilitate planning, delivery and evaluation of study programs and student mobility by recognising learning achievements and qualifications and periods of learning. 
Flexibility Refers to measures through which the provision of higher education is made more flexible. The idea behind this concept is to open up higher education to more people and to increase adaptability to the multiple life worlds in modern societies. It also relates to flexibility in program/curriculum design and approaches to learning and teaching.

Formal learning means formally structured and recognised learning.

'non-formal learning' means learning that takes place through a structured and/or unstructured process of learning but does not lead to a formally recognised qualification. Typically, it may include workshops, community courses, e-learning programs, interest based courses, short courses, or conference/forum style seminars.

'informal learning' means semi-structured or nonstructured learning that occurs over time and in a variety of places through experiences, such as learning at home, work, life, family, social, leisure activities, and through daily interactions and shared relationships among members of society. Unlike formal or non-formal learning, informal learning is not organised or externally structured in terms of standards, objectives, time or learning support, but may be accredited.

Institutional Research is a system that provides the institution with the capability to determine whether the objectives of its academic, student, and administrative service units, and the LOs of its academic programs and courses, are being met.

Learning pathway is a route taken by a learner allowing him/her to build knowledge progressively and acquire the desired set of competences. The learning pathway may be 'signposted' through institution guidance and regulations (including the recognition of prior learning and experience) and different learning pathways may lead to the award of the same qualification. In essence the concept of a 'learning pathway' emphasises the choice of the student in reaching the desired educational goals.

Lifelong learning (LLL) All learning activity undertaken throughout life, with the aim of improving knowledge, skills and competences within a personal, civic, social and/or employment-related perspective. Programs and services contributing to lifelong learning within the higher education sector may include mainstream programs, continuing education, evening classes, specific programs for part-time learners, access to libraries/higher education institution resources, distance learning, training courses, targeted guidance and counselling services among other actions and initiatives.

National Qualifications Frameworks (NQF) An instrument for the classification of qualifications according to a set of criteria for specified levels of learning achieved, which aims to integrate and coordinate national qualifications subsystems and improve the transparency, access, progression and quality of qualifications in relation to the labour market and civil society.

OBE Outcome Based Education, a method of curriculum design and teaching that focuses on what students gained and actually do after they are taught.

Student-Centred Learning (SCL) A learning approach characterised by innovative methods of teaching which aim to promote learning in communication with teachers and students and which takes students seriously as active participants in their own learning, fostering transferable skills such as problem-solving, critical and reflective thinking.

Workload An estimation of the time learners typically need to complete all learning activities such as lectures, seminars, projects, practical work, work placements, individual study required to achieve the defined learning outcomes in formal learning environments. The correspondence of the fulltime workload of an academic year to 60 credits is often formalised by national legal provisions. In most cases, student workload ranges from 1,500 to 1,800 hours for an academic year, which means that one credit corresponds to 25 to 30 hours of work. It should be recognised that this represents the normal workload and that for individual learners the actual time to achieve the learning outcomes will vary.

Work placement A planned period of experience outside the institution (for example, in a workplace) to help students to develop particular skills, knowledge or understanding as part of their program. 